\title{
IMPROVING PRODUCTIVITY AND STANDARD TIME UPDATING IN AN INDUSTRIAL COMPANY - A CASE STUDY
}

\author{
Mariana Araújo, Gabriela Amaral, Leonilde Varela \\ University of Minho, Department of Production Systems, Campus of Azurém, 4800-058 Guimarães, Portugal
}

\begin{abstract}
Today's marketplace imposes ever-tightening product pricing and quality requirements, shorter delivery times, and increasingly customized products. With increasing competition in today's global market, companies are increasingly pressured to improve the performance of their production systems in order to be more competitive and improve market share. In order to try to satisfy these requirements several companies seek for the application of methodologies that may enable them to respond to these challenges, such as the ones based on the Lean Manufacturing philosophy. In this work standard times of four extruders are determined and updated in the context of setup time's analysis and minimization in a company, in Portugal. First, a diagnosis is made to the tire floor extrusion process in order to evaluate all of its inefficiencies with the greatest impact on the production process, after the standard time of each extruder is analysed and updated through an extended approach which does also consider setup times reduction, along with the production times, for reaching a higher process optimization rate and productivity in the underlying production system.
\end{abstract}

Keywords: Productivity, Standard time, Tire floor extrusion, Industrial development.

\section{Introduction}

With the increasing competition in today's global market, companies are increasingly being pressured to improve the performance of their production systems in order to be more competitive, efficient and to improve market share [1].

Being aware of the today's market laws demands companies to be more dynamic with high quality and reduced response times while the ratios between costs and revenues are becoming smaller, and becoming more difficult and complex to meet the customer's requirements. The current market imposes the price of products, increasingly tight quality requirements, shorter delivery times and not neglecting also the requirement of increasingly personalized products. Therefore, several companies seek to find methodologies that allow them to respond to these challenges, being the philosophy of Lean Manufacturing and closely related approached, such as methods and times measurement and analysis the solution often chosen by many companies [15].

The present aims at determining and updating the standard time of four extruders in a Company, while determining and optimizing setup times in the production process.

Initially, a diagnosis was made to the tire trellis extrusion process in order to evaluate all of its inefficiencies with the greatest impact on the production system as well as to update the standard time of each extruder. This analysis was performed in different work shifts, including different work teams to obtain a more representative sample of the global processing scenario.

\section{Literature Review}

The companies seek to find methodologies that allow them to respond to the growing challenges that are currently posed to them, and the Lean Manufacturing philosophy $[1,2,8,13,15,16]$ and some other more or less closely related subjects are often the solution found to solve their problems [5$7,9,11,14,15,17,18]$.

The goal of Lean Manufacturing is to minimize any kind of waste, which becomes a progressively more complex goal to achieve, to make each company more competitive in the current global market context $[13,15,16]$.

This philosophy, which was originated in the Toyota Motor Corporation on the underlying Toyota Production System, follows a management concept that seeks to reduce activities that do not add value to the product along the production chain [1], thus aiming at the improvement of the production processes. This philosophy emerged in Japan in a Toyota car factory after World War II, pioneered by Eiji Toyoda and Taiichi Ohno [16]. Faced with the needs of the market, the Toyota car factory had the 
need to develop a new production philosophy called Toyota Production System, to solve the paradigm in which, using few resources, it was possible to offer a high variety of products with great quality and enabling competitive prices. Therefore, the Toyota Production System (TPS) consists on eliminating waste and continuously improving a production process, while optimizing the use of resources [16].

According to Ohno, in 1988 [12] the base of support of the TPS consists of two pillars: the autonomation, also known by jidoka and the just-intime (JIT) philosophy. Autonomation consists of the ability that equipment must have to stop when anomalies arise, thus avoiding products with defects. The just-in-time philosophy consists in producing what is really necessary, in terms of quantity, thus avoiding waste [12].

Womack and Roos, in 1990 [16] defined five fundamental principles for reducing waste:

- Identify value: differentiate activities that add value to the product and differentiate them from waste;

- Value Chain: map the product's processing chain to identify and eliminate waste;

- Flow: work the product at each step of the process to avoid waits and obstacles in the process;

- Pulled production: let the production be "pulled" by the customer, and produce only what is ordered by the customer;

- Continuous improvement: there is always room for improvement, there are no perfect systems.

To achieve process improvement there are several tools associated with this lean philosophy. In the context of this work are included the tools about time and methods measurement and analysis, and to support the determination of Standard Time, along with the $5 \mathrm{~S}$ principles.

\section{Times and Methods}

The productivity enhancement process in companies usually aims at the improvement of the resources usage, in order to make them more profitable. The maximization of resources utilization can be accomplished by numerous means, such as the socalled Work Study, which is a term generally used to describe a set of tools and techniques of analysis applied when we study the work carried out by operators on a factory, independently of the manufacturing context.

This analysis usually involves a systematic study of all factors that may affect, or come to affect, the effectiveness, aiming at an improvement of the whole production process.

When analysing the total duration of a given operation, the following times are considered:
The total duration of the operation is divided by the time inherent in the total work content (which consists of fundamental work content, supplementary work content due to design defects of product and supplementary work content by the use of incorrect execution methods) and total unproductive time (which is constituted by unproductive time due to inadequate management and unproductive time attributed to the worker).

The core work content designates all the activities precisely necessary to perform the operation using the most correct manufacturing methods and the most appropriate machines, excluding all activities that are not really necessary for the operation to meet quality standards and all specifications. Summarizing, fundamental work content can be defined as the minimum irreducible work required for the correct execution of a considered operation.

All activities that do not comply with the concept of fundamental work content are considered as supplementary work content.

The study of work, or study of times and movements, focuses on the study of the work context considering the optimization of existing resources. Briefly, the work study focuses on existing operations, processes and working methods, in order to examine the possibility of increasing effectiveness.

The study of methods consists of recording and analyzing, in a critical and systematic way, the current and planned methods for the execution of certain activities. Its general objective is to improve methods in order to make its execution more convenient, efficient and less costly. The main objectives of these techniques are to improve processes and methods of implementation; improving the deployment and layout of workstations and the design of installations and equipment; save human effort and reduce useless fatigue; improve the use of material, machinery and labor, and finally create favorable working conditions.

The work measurement consists in the application of a set of techniques, in order to determine the time necessary for a skilled worker to perform a given task, with a well defined process, in order to reach a productivity improvement [4].

To achieve the objectives it is necessary to carry out a rigorous and accurate study in the collection and analysis of the observed data. 


\section{Standard Working Time and Measurement}

One of the components of the work study is the measure of work, which is a set of procedures used to determine the time required, under certain standardized measurement conditions, to perform tasks involving human activity. The result of this determination is called Standard Time (ST).

The fundamental use of Standard Time is to provide management with a quantitative value that enables it to determine the manpower resources that are required to perform a given task whose activities that are to be performed in its execution are known and precisely defined. The ST consists of a numerical value that allows quantifying the work content of a given operation, accordingly described and defined with the appropriate techniques of the Study of Methods. With the ST it is possible to determine the human resources needed to carry out an operation, to forecast the execution times of the manufacturing tasks and thus to plan production properly, being essential for the definition of order delivery times and labour costs - plan for realistic budgets, for the comparison between planned and current manpower.

Briefly, if the Study of Methods aims at reducing the content of work, that is, to eliminate the useless movements of men and materials and to substitute less appropriate methods for more efficient ones, the Measure of Work is intended to measure the work content of operations by measuring run time. This way we can identify, reduce and eliminate unproductive times while improving processes and productivity rates in factories.

The type of work to be measured determines the technique to be used in the measurement of work. The method chosen will be based on several factors, such as the type of activity (if the work is repetitive short cycle, work without repetitive cycles or with very long cycles) or the time available to carry out the study.

The following are the main techniques used in the measurement of work [4]:

- Time or timing study: Intensive or continuous direct observation technique, suitable for manual or semiautomatic tasks of short and repetitive cycles;

- Work sampling or probing: extensive direct observation technique suitable for work without repetitive cycles or with very long cycles;

- Predetermined time systems: times of execution of repetitive operations of very short cycle that cannot be observed;

- Reference data system or synthetic times: used in long-term activities and many variables.

\section{Time Study}

Time Study is a direct and intensive observation measurement technique, which consists of recording times and conditions for performing a task and analyzing the data collected to obtain the execution time at a well-defined performance level.

The time measurement is done with timing, where the operator's work rhythm is observed and classified. Other factors are also recorded, such as working conditions, irregular situations, among others, with influence on execution times. There are fundamental prerequisites to succeed in the study of times, such as [10]:

1. The method of studying the times to be used shall be carefully chosen, explained and agreed by the management and employees of the Company;

2. The precision intended for the study should be predefined;

3. The workers to be analyzed must be selected from the full-time employees of the Company;

4. The workers to be analyze must be motivated for the success of the study;

5. The time agent shall be qualified, credible and objective;

6. The tolerances and corrections assigned must be correctly defined;

7. Supervisors should have detailed knowledge of the study before it is explained to all workers involved.

The activity should be broken down into elements, which it is important to choose, according to the following criteria [4]:

An operation element will be each distinct part of a given activity, task or operation, comprising one or several fundamental movements of the performer, or movements of the machine or stages of the process; Duty Cycle is a complete series of elements required to perform an activity, task or operation to acquire a production unit. They may include elements that do not happen at all cycles.

The elements can be repetitive, constant, variable, occasional or extraneous to the operation.

The repetitive elements are found in all cycles; the constants, with identical characteristics and duration, are in one or several operations; the variables are the elements that have variation of the execution time according to the characteristics of the product, material or process; the occasional ones may or may not appear at regular intervals and those that are different are called irregular occurrences and there are still elements that are foreign to the operation, that is, those that may occur during a study, but are not necessarily part of a operation.

To perform and facilitate a time-by-time study, it is necessary to take into account a set of steps, such as [19]: 
1. Obtain information about operations and operators.

2. Divide operations into their elements and record a complete description of the process.

3. Observe and record the operator's time in elementary operations.

4. Determine the number of cycles to be timed.

5. Evaluate operators' performance.

6. Determine the Cycle Time (Tz):

$$
T z=\frac{\sum T z}{\text { number of measurements }}
$$

7. Determine Corrections

8. Determine the Standard Time for each operation i (STi):

$$
S T i=\left(O T \times \frac{\overline{A F i}}{R A}\right) \times(1+\Sigma C i)
$$

being:

$O T$ - the observed time;

$(A F i)$ - the average activity factor for operation i;

$R A$ - the reference activity (in general, $\mathrm{RA}=100$ );

$\Sigma C i$ - the sum of all the corrections considered.

\section{Problem Description}

The final product of the company where this study was carried out is the tire. This varies in several characteristics, such as measures and brand, taking into account the target market. Regarding the measures, the company produces tires from rim 14 to 21 .

Next a brief description of the different parts constituting a car tire, according to Figure 1, is provided.

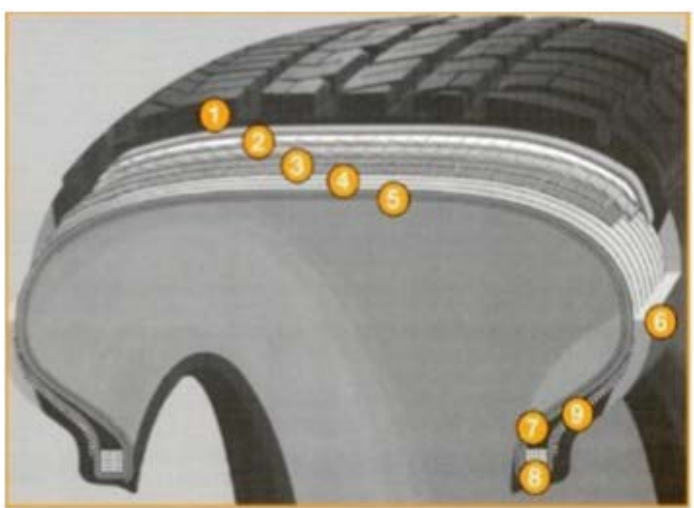

Fig. 1. Tire Structure [3]. Legend: 1 - Tire tread, 2 - Spiral textile band, 3 - Metal strip, 4 - Textile tire, 5 - Watertight layer, 6 - Tire wall, 7 - Tire bead wedge, 8 - Tire bead core, 9 - Tire bead reinforcement.

In this work, the main problem to be solved in the company was related to the attempt to adapt the general formula for the determination of standard times to the determination of setup times, in order also to include corrections on it, as being an important part not to be ignored when determining setup times, since these can play an important role in the correct dimensioning of this type of time.

Thus, in this work, a fundamental aspect consisted in the contribution with the inclusion of the parameter of corrections, in addition to the other traditional parameters included in the determination of standard times, when calculating setup times.

\section{Setup Time Determination as a Standard Time}

In the study carried out we used the zero-return timings, during which the setup times were recorded. With these data, a time recording sheet with a sample of 15 times, non-cyclical due to the working conditions of the stage was created, so it was not possible to collect cyclic data by extruders.

Depending on the type of setup, the setup process was divided in several phases and the performance and work corrections were affected to the manual operation times. Some times were eliminated due to the fact that they were outliers, not representative of the samples for the times collected per cycle analyzed.

On each extruder there were considered three types of setup, the die setup, the cover change setup and the last change of base and cover setup. The data obtained for the analyzed extruders are shown in Table 1 below.

With the samples considered it could be verified that the extruders did not always present similar results, and this is mainly due to being present a greater variation of the cycle times in some of them, as the unit times for each phase of the process did vary. 
Table 1. Data obtained for the different extruders

\begin{tabular}{llllll}
\hline $\mathbf{n}$ & $\overline{\boldsymbol{t}_{\boldsymbol{z}}}[\mathbf{s e c}]$ & $\overline{\boldsymbol{R}_{\boldsymbol{z}}}[\mathbf{s e c}]$ & $\mathbf{s}$ & $\mathbf{v}$ & $\mathbf{N}$ \\
\hline 12.00 & 299.00 & 195.00 & 86.70 & 29.00 & 129 \\
14.00 & 403.00 & 175.00 & 75.30 & 18.70 & 54 \\
13.00 & 840.00 & 441.00 & 236.00 & 28.00 & 121 \\
\hline 14.00 & 255.00 & 130.00 & 65.40 & 25.60 & 101 \\
15.00 & 577.00 & 38.00 & 159.00 & 27.50 & 116 \\
15.00 & 678.00 & 229.00 & 98.80 & 14.60 & 33 \\
\hline 15.00 & 242.00 & 61.00 & 26.90 & 11.10 & 19 \\
15.00 & 360.00 & 117.00 & 42.10 & 11.70 & 21 \\
15.00 & 804.00 & 258.00 & 115.00 & 14.30 & 31 \\
\hline 15.00 & 185.00 & 60.00 & 22.80 & 12.30 & 23 \\
14.00 & 349.00 & 226.00 & 94.40 & 27.00 & 112 \\
15.00 & 760.00 & 180.00 & 118.00 & 15.60 & 37 \\
\hline
\end{tabular}

This is due to the fact that not just the employees have a procedure and a non-uniform working process, but also other related factors, such as the varying extruder speed, type of material and type of setup change.

Regarding the previous data obtained in the Company, we verified that the values are within the established values, not having much variation, independently of the number of cycles to be necessary to calculate and the use of the standard time equation enabled to reach more valuable and precise values for the setup times of the Company's extruders.

\section{Conclusions}

The main objective of this work was to determine the standard times and setup times and to analyze the disturbances of the production process of a Portuguese tire floor extruders company. For these objectives to be achieved, the whole tire floor extrusion process was analyzed, using different types of setup on each extruder and analyzing the types of existing and most common disturbances during a run in the tire floor extrusion process.

After analyzing the data obtained it was found that the values did vary. The differences between the standard setup times per extruder and type are due to the fact that the employees cooperate with each other through the division of tasks and procedures and the number of phases inherent to the setups are also different.

Another kind of improvement reached at the company was due to the use of Lean 5 s tool. The extruder tool table was organized to make it easier and quicker to obtain the necessary tool for each kind of setup. Through this work carried out in the Extrusion section of the company some relevant opportunities for improvement of the efficiency of the productive process were reached.

Standard time corrections analyzed enables to realize in a more detail a precise evolution of the disturbances that occur during a race, that is, considering the occurrences that affect all the time spent per day and the disturbances, divided by the duration of the daily working period.

Similarly, corrective actions were applied to the disturbances with the greatest impact on the production of tire floors, and a detailed analysis of its causes was carried out, which is very important for further understanding some discrepancies occurring within the setup standard times of the extruders' tire floor production processes.

\section{Acknowledgements}

This work has been supported by COMPETE: POCI01-0145-FEDER-007043 and FCT - Portuguese Foundation for Science and Technlology within the Project Scope: UID/CEC/00319/2013.

\section{References}

[1] Abdulmalek, F.A.: Analyzing the benefits of Lean manufacturing and value stream mapping via simulation. International Journal of Production Economics (2007).

[2] Al-Ashaab, A., \& Sobek, D. K.: Lean manufacturing and process development: a value creation paradigm that goes beyond Lean manufacturing. International Journal of Computer Integrated Manufacturing, 26 (12), 1103-1104 (2013). Doi: 10.1080 / 0951192x.2013.834483.

[3] Araújo, M.: Masters dissertation on Industrial Engineering, University of Minho (2016).

[4] Costa, L.F.T., Gomes, A., Pedro, M.F.M.: Introduction to work study. Guimarães (2003). 
[5] Coutinho, C.P., Sousa, A., Dias, A., Bessa, F., Ferreira, M., Rodrigues, J.C.: Action research preferred methodology in educational practices. Revista Psicologia, Educação e Cultura. ISSN 0874-2391. 13: 2 (Dec. 2009) 355-379 (2009).

[6] Gosling, J., \& Naim, M. M.: Engineer-to-order supply chain management - A literature review and research agenda. International Journal of Production Economics, 122 (2), 741-754 (2009). Doi:

http://dx.doi.org/10.1016/j.ijpe.2009.07.002

[7] Jang, Y., Lee, J.: Factors influencing the success of management consulting projects. International Journal of Project Management, 16 (2), 67-72 (1998). Doi: http://dx.doi.org/10.1016/S02637863(97)00005-7.

[8] Krafcik, J.F.: Triumph of the Lean Production System. Sloan Management Review, 30 (1), 4151 (1988).

[9] Lu, R. F., Petersen, T. D., Storch, R. L.: Asynchronous stochastic learning curve effects in engineering-to-order customization processes. International Journal of Production Research, 47 (5), 1309-1329 (2009). Doi: 10.1080 / 00207540701484921.

[10] Levine, G.: The fate of time study, The Industrial Advisor, Gene Levine and Associates, September (1997).

[11] Moreira, D.A.: Production management and operations. 1st ed, Pioneer Thomson Learning, (1993). ISBN 85-221-0135-3.
[12] Ohno, T.: Toyota production system: beyond large-scale production. New York: Productivity Press (1988).

[13] Ortiz, C.A.: Kaizen Assembly: Designing, Constructing, and Managing a Lean Assembly Line. New York: CRC Press (2006).

[14] Radke, A. M., Tseng, M. M.: A risk management-based approach to inventory planning of engineering-to-order production. Cirp Annals-Manufacturing Technology, 61 (1), 387-390 (2012). Doi: 10.1016 / j.cirp.2012.03.064.

[15] Taggart, P., Kienhoefer, F.: The effectiveness of lean manufacturing audits in measuring operational performance improvements. South African Journal of Industrial Engineering, 24 (2), 140-154 (2013).

[16] Womack, J., Jones, D., \& Roos, D.: The machine that changed the world: the story of Lean Production. New York: Rawson Associates (1990).

[17] Leão, C.P., Soares, F., Rodrigues, H., Seabra, E., Machado, J., Farinha, P., Costa, S., "Web-assisted laboratory for control education: Remote and virtual environments" (2012) Communications in Computer and Information Science, 282 CCIS, pp. 62-72. DOI: 10.1007/978-3-642-28816-6_7

[18] Womack, J.P., Jones, D.T.: Lean Thinking: Banish Waste and Create Wealth in Your Corporation, New York, USA: Simon \& Schuster (1996).

[19] Xavier, D., Botelho, S., Silva, M.: Time study to increase productivity in construction (2001). 